\title{
Sikap Generasi “'Z”' terhadap bahasa Jawa: Studi kasus pada anak-anak usia Sekolah Dasar di kota Semarang
}

\author{
Ilham Setyawan \\ Magister Ilmu Komunikasi Fakultas Ilmu Sosial dan Ilmu Politik \\ Universitas Diponegoro Semarang \\ ilhamsetyawan456@gmail.com
}

\begin{abstract}
Abtract
Language in everyday life has a very important role in communicating. At present there has been a decline in interest in the use of Javanese as a communication tool for the " $Z$ " generation, namely the generation born in 1994-2012. The aim of this study is to find out the intensity of the use of regional languages, especially the Javanese language by the " $Z$ " generation, what is the impact of the loss of regional languages, especially the Javanese language for the identity of the region and how the generation of " $Z$ " language attitudes to local languages are specifically Javanese. From this study it was found that, " $Z$ " generation has the ability that is very lacking in communicating using Javanese. The things that affect their mastery in language include their buccal background originating from the Javanese, the lack of use of the Javanese language as a daily communication tool and the lack of innovation in Javanese language learning methods. From this, innovation in learning is needed as well as increasing the intensity of the use of Javanese as a daily communication tool. Parents and teachers in the school have a role in mastering the Javanese language in communicating.
\end{abstract}

Keywords: "Z” generation, language skills, attitude

\section{PENDAHULUAN}

Dalam kehidupan sehari-hari, bahasa adalah elemen terpenting dalam berkomunikasi. Dengan menggunakan bahasa, seseorang dapat memahami apa yang menjadi maksud dan tujuan kita. Bahasa dapat dikatakan sebagai salah satu media kita untuk berinteraksi satu dengan yang lainnya. Baik itu menggunakan bahasa dalam bentuk lisan maupun tulisan.

Negara Indonesia adalah negara yang kaya akan budaya. Margaret Mead mengemukakan bahwa budaya adalah perilaku yang dipelajari dari sebuah masyarakat atau sub kelompok (Sutarno, 2007). Salah satu contoh kekayaan budaya tersebut adalah banyaknya bahasa daerah yang tersebar di seluruh wilayah Negara Kesatuan Republik Indonesia. Sebagian besar suku-suku di Indonesia memiliki bahasa sendiri yang digunakan untuk berinteraksi sehari-hari di dalam kehidupan masyarakat. Penelitian untuk pemetaan bahasa di Indonesia yang dilaksanakan Badan Pengembangan dan Pembinaan Bahasa, Kementerian Pendidikan dan Kebudayaan dilakukan sejak 1991 hingga 2017. Bahasa daerah (tidak termasuk dialek dan subdialek) di Indonesia yang telah diidentifikasi dan divalidasi sebanyak 668 bahasa dari 2.468 daerah pengamatan. Jika berdasarkan akumulasi persebaran bahasa daerah per provinsi, bahasa di Indonesia berjumlah 750 (Akuntono, 2012). 
Data SIL (Summer Institute of Linguistic) menunjukan adanya 735 bahasa daerah di Indonesia (Mulyana, 2008). Dari 735 bahasa daerah tersebut 83 dinyatakan sehat karena penuturnya 100.000 atau lebih. Sisanya, 637 dalam kondisi mengkhawatirkan, 12 tidak diketahui, dan 3 dinyatakan punah. Diantara yang mengkhawatirkan tersebut sebanyak 32 bahasa daerah dalam kondisi nyaris punah karena tinggal memiliki penutur 1-50 orang.

Dwi Bambang Putut Setiyadi menyatakan bahwa banyaknya bahasa daerah yang hampir punah disebabkan karena siswa atau generasi muda kurang menghargai bahasa ibu sebagai bahasa daerahnya (Mulyana, 2008). Tak terkecuali bahasa Jawa yang saat ini juga mulai tersisihkan. Beberapa orang beranggapan bahwa pemakaian bahasa Jawa sebagai alat komunikasi dalam kehidupan seharihari sebagai penanda ketidakmajuan atau ketinggalan jaman, sehingga intensitas penggunaan bahasa Jawa semakin berkurang dan intensitas penggunaan bahasa Indonesia dan bahasa internasional semakin meningkat. Belakangan ini bahasa Jawa sudah mengalami kemunduran secara fungsional, hal ini disebabkan oleh terus menyempitnya pemahaman terhadap jagat kata bahasa Jawa.

Faktor yang paling dominan dari hal tersebut adalah kurangnya pendidikan berbahasa Jawa dengan baik di lingkungan keluarga. Orang tua tidak memperhatikan bahwa kurangnya pendidikan dalam keluarga akan mengakibatkan anak-anak tidak dapat menggunakan bahasa Jawa dengan benar, yang akhirnya kaum muda jika berkomunikasi dengan orang tua menggunakan bahasa Jawa yang sudah "rusak" (Widada, 1993). Faktor lain adalah lingkungan. Lingkungan yang kurang mendukung mereka untuk selalu menggunakan bahasa Jawa dalam mereka berkomunikasi. Yang kedua secara tidak kita sadari tingkat mobilitas penduduk yang semakin tinggi juga berpengaruh. Berpindahnya orang-orang kota ke wilayah pedesaan serta banyak dibangunnya perumahan di dekat atau di daerah pedesaan sehingga banyak pendatang yang latar belakangnya bukan orang Jawa juga berpengaruh terhadap menurunnya intensitas pemakaian bahasa Jawa. Pergaulan kita dengan orang yang tidak bisa berbahasa Jawa mau tidak mau memaksa kita untuk menyesuaikan dengan mereka dalam kita berkomunikasi (Juhroti, 2011).

Berkaitan dengan sikap generasi "Z" saat ini tentang penggunaan bahasa Jawa sebagai alat komunikasi dalam kehidupan sehari-hari hari terungkap dalam wawancara dan obeservasi awal bahwa salah satu anak tidak merasa bangga menggunakan Bahasa Daerah, melainkan dia lebih bangga menggunakan Bahasa Inggris untuk digunakan dalam sehari harinya. Faktor lain yang ditemukan adalah bahwa orang tua tidak mengajarkan Bahasa Indonesia maupun Bahasa Daerah di lingkungan rumah. Selain itu dari hasil observasi yang telah dilakukan terungkap bahwa, generasi "Z" masih kesulitan dan jarang sekali berkomunikasi menggunakan bahasa Jawa. Namun mereka tidak kehilangan minat untuk belajar bahasa Jawa. Dari adanya beberapa fenomena yang terjadi di atas, mendorong penulis untuk melakukan penelitian tentang sikap generasi "Z" terhadap bahasa Jawa.

Tujuan yang igin didapatkan dari adanya penelitian ini adalah, bagaimana intensitas penggunaan bahasa daerah khususnya bahasa jawa oleh para generasi " $Z$ ", apa dampak dari hilangnya atau punahnya bahasa daerah khususnya bahasa jawa bagi identitas daerah tersebut dan bagaimana sikap bahasa generasi " $Z$ " terhadap bahasa daerah kususnya bahasa Jawa 


\section{LITERATUR PUSTAKA}

Bahasa Jawa adalah bahasa ibu (mother tongue ) dengan jumlah penutur yang besar. Menurut Grimes, secara internasional Bahasa Jawa menempati urutan ke-11, dengan jumlah penutur 75.500.000. Secara kuantitatif jumlah tersebut sangat besar, tetapi secara kualitatif kondisi Bahasa Jawa semakin merosot (Subroto, Dwiraharjo, \& Setyawan, 2007). dan mulai ditinggalkan penuturnya. Di satu sisi Bahasa Jawa merupakan aset budaya yang adi luhung, di sisi lain Bahasa Jawa kalah bersaing dengan Bahasa Indonesia dan Bahasa Asing. Bahasa Jawa dengan tingkat tuturnya membentuk watak yang luhur, rendah hati dan menghormati orang lain, sebaliknya Bahasa Indonesia dan Bahasa Asing lebih berorientasi pada keberhasilan di bidang materi. Dewasa ini masyarakat Jawa lebih cenderung mengarah pada keberhasilan di bidang ekonomi dibandingkan mempertahankan budaya Jawa yang lebih menekankan pada aspek moral.

Menggunakan bahasa Jawa untuk berkomunikasi dengan sesama pengguna bahasa Jawa adalah salah satu cara untuk melestarikan bahasa Jawa. Akan tetapi, ironisnya sekarang ini pengguna sekaligus pemilik bahasa Jawa sudah enggan menggunakannya, bahkan sudah ada yang mulai meninggalkannya.

Belakangan ini bahasa Jawa sudah mengalami kemunduran secara fungsional, hal ini disebabkan oleh terus menyempitnya pemahaman terhadap jagat kata bahasa Jawa. Selain itu pengajaran bahasa terancam bubar karena tidak ada petunjuk pelaksanaannya, adanya kecemburuan bahkan rasa malu dikalangan generasi tua terhadap upaya pembaharuan kreatif pemanfaatan kosakata bahasa Jawa secara maksimal oleh generasi muda juga menjadi salah satu penyebab kemunduran fungsional bahasa Jawa (Mardianto, 1993). Semua itu jelas terlihat pada kenyataan sekarang, di mana anak-anak sekarang yang akan menjadi generasi penerus yang peduli dan diharapkan akan menjaga bahasa Jawa agar tetap lestari lebih memilih menggunakan bahasa Indonesia atau bahasa internasional untuk berkomunikasi.

Faktor yang paling dominan dari hal tersebut adalah kurangnya pendidikan berbahasa Jawa dengan baik di lingkungan keluarga. Orang tua tidak memperhatikan bahwa kurangnya pendidikan dalam keluarga akan mengakibatkan anak-anak tidak dapat menggunakan bahasa Jawa dengan benar, yang akhirnya kaum muda jika berkomunikasi dengan orang tua menggunakan bahasa Indonesia atau dengan bahasa Jawa yang sudah "rusak" (Widada, 1993). Faktor lain adalah lingkungan. Lingkungan yang kurang mendukung mereka untuk selalu menggunakan bahasa Jawa ragam krama dalam mereka berkomunikasi. Yang kedua secara tidak kita sadari tingkat mobilitas penduduk yang semakin tinggi juga berpengaruh. Berpindahnya orang-orang kota ke wilayah pedesaan serta banyak dibangunnya perumahan di dekat atau di daerah pedesaan sehingga banyak pendatang yang latar belakangnya bukan orang Jawa juga berpengaruh terhadap menurunnya intensitas pemakaian bahasa Jawa. Pergaulan kita dengan orang yang tidak bisa berbahasa Jawa mau tidak mau memaksa kita untuk menyesuaikan dengan mereka dalam kita berkomunikasi.

Pada kenyataannya memang sebagian masih ada yang berkomunikasi menggunakan bahasa Jawa dalam keseharian mereka, tetapi bahasa Jawa yang digunakan hanya bahasa Jawa ragam ngoko. Ragam krama yang dalam pemakaiannya dapat secara langsung sebagai sarana menghormati lawan bicara kita, tinggal sedikit 
yang menggunakan. Kenyatan yang banyak terjadi sekarang adalah orang Jawa yang menggunakan bahasa Jawa khususnya bahasa Jawa ragam krama hanya orang-orang di pedesaan, sedangkan bagi masyarakat Jawa yang berdomisili di kota sudah jarang menggunakan bahasa Jawa, bahkan tidak sedikit yang tidak bisa berbahasa Jawa ragam krama.

Sikap kurang positif terhadap bahasa Jawa yang melanda orang tua terutama dari golongan modern sudah sering kita jumpai.Biasanya mereka lebih menomersatukan bahasa Indonesia sebagai bahasa dalam keluarga, yang secara otomatis menganaktirikan bahasa Jawa yang justru merupakan bahasa ibu.

Dalam pidato pengukuhannya sebagai Guru Besar Fakultas Sastra dan Seni Rupa Universitas Sebelas Maret Surakarta, Sumarlam, mengatakan generasi muda Jawa sekarang ini ada kecenderungan enggan berkomunikasi menggunakan bahasa Jawa terutama dengan orang lebih tua karena takut salah dan dinilai tidak mempunyai tata karma (Yudhono, 2011). Sumarlam juga mengungkapkan bahwa, Orang Jawa dalam berkomunikasi tidak segan lagi mencampurkan struktur dan kosakata bahasa tertentu, misalnya struktur dan kosakata bahasa Indonesia atau bahasa asing ke dalam bahasa Jawa (Yudhono, 2011).

\section{METODE PENELITIAN}

Dalam penelitian ini proses dimulai dari tahap penyediaan data, reduksi atau seleksi data, display atau penyajian data, dan pengambilan kesimpulan data. Proses di atas tidak berjalan secara linear tetapi bersifat simultan atau siklus yang interaktif. Adapun tahapan yang dilakukan adalah sebagai berikut: (1) Pengumpulan data; (2) Tahap reduksi data (seleksi data); (3) Melaksanakan kegiatan display atan penyajian data; (4) Membuat simpulan sementara dan menguji kembali dengan metode triangulasi, baik menggunakan triangulasi data dan teori; dan (5) Tahap terakhir, yaitu membuat pernyataan atau simpulan secara bulat tentang suatu masalah yang diteliti dalam bahasa kualitatif yang diskriptif dan bersifat interpretatif.

Untuk mendapatkan data dari penelitian ini, penulis menggunakan teknik kuesioner yang kemudian diperdalam dengan wawancara untuk bisa mendapatkan data lebih akurat. Hal ini mengingat responden utama dari penelitian ini adalah anak-anak usia Sekolah Dasar yang masih memerlukan pendampingan dalam menjawab pertanyaan-pertanyaan dari kuesioner yang diberikan oleh peneliti. Penulis juga melakukan wawancara terhadap beberapa orang tua dari responden utama untuk bisa mendapatakna penggambaran yang lebih jelas dari permasalahan yang diungkapkan dalam penelitian ini.

Dalam penelitian ini, penulis menggunakan anak usia Sekolah Dasar sebagai responden penelitian utama. Pemilihan anak usia Sekolah Dasar sebagai responden utama sebagaimana pemahaman tentang generasi " $Z$ " yang dimaksud dalam penelitian ini.

Generasi "Z" yang dimaksud dalam penelitian ini adalah sebagaimana yang dimaksud oleh Mc-Crindle, yaitu generasi yang lahir pada tahun 1995 hingga tahun 2010. Generasi ini adalah generasi yang paling akrab dengan perkembangan teknologi informasi. Penggunaan gadget pada generasi ini telah menjadi sebuah kebiasaan yang sangat lumrah. 
Penelitian ini menggunakan tipe penelitian deskriptip dengan menggunakan pendekatan kuantitatif. Metode penelitian kuantitatif sebagaimana diungkapkan oleh Sugiyono yaitu, metode penelitian yang berlandaskan pada filsafat positivisme, digunakan untuk meneliti pada populasi atau sampel tertentu, pengumpulan data menggunakan instrumen penelitian, analisis data bersifat kuantitatif/statistik, dengan tujuan untuk menguji hipotesis yang telah ditetapkan (Sugiyono, 2012). Penelitian deskriptif dalam penelitian ini dimaksudkan untuk mendapatkan gambaran dan keterangan-keterangan mengenai sikap dari generasi " $Z$ ” terhadap bahasa Jawa.

\section{HASIL DAN PEMBAHASAN}

Untuk memperoleh hasil sesuai dengan ekspetasi, peneliti memilih siswa Sekolah Dasar kelas 4 hingga 6 sebagai responden dari penelitian ini.

Ssebagaimana dijelaskan pada teori, salah satu hal mendasar seorang anak untuk bisa memahami tentang suatu bahasa, diantaranya dipengaruhi oleh latar belakang dari si anak tersebut. Dalam penelitian ini terungkap bahwa hanya $13 \%$ responden dari penelitian ini mengaku berasal dari Suku Jawa. Hal ini dapat dimaklumi karena responden dari penelitian ini berasal dari multikultural. Adanya responden yang multikultural adalah salah satu karakteristik yang terdapat di sekolah-sekolah yang ada di kota besar, yang mana penduduknya memiliki heterogenitas dalam kultur budaya.

Pengetahuan tentang bahasa juga sangat diperlukan seorang anak untuk mempelajari dan memahami tentang suatu bahasa. Dari penelitian ini terlihat bahwa, $13 \%$ responden tidak mengenal tentang bahasa Jawa, adanya hal ini menjadikan pengaruh terhadap tingkat kemampuan seorang anak untuk melakukan komunikasi dalam bahasa Jawa. Dalam penelitian ini terungkap bahwa $63 \%$ responden tidak mampu berkomunikasi dengan menggunakan bahasa Jawa pada level dasar. Level dasar komunikasi dengan menggunakan bahasa Jawa yang dimaksud dalam penelitian ini adalah berkomunikasi dengan menggunakan bahawa "Jawa Ngoko". Adanya fakta tentang kemampuan berkomunikasi dalam bahasa Jawa level dasar, tentunya sangat berpengaruh pada kemampuan seorang anak dalam berkomunikasi dengan menggunakan bahasa Jawa dalam level menengah (bahasa Krama). Pada level ini terungkap bahwa, hanya $20 \%$ responden memiliki kemampuan untuk berkomunikasi dengan menggunakan bahasa Jawa Krama.

Lingkungan memiliki peran yang sangat penting bagi seorang anak untuk mampu berkomunikasi dalam bahasa Jawa. Lingkungan yang dimaksud di sini diantara adalah mengenai latar belakang dari orangtua dan penggunaan bahasa Jawa dalam kehidupan sehari-hari. Dari penelitian ini terungkap bahwa, 33\% orangtua responden tidak memiliki latar belakang budaya dari suku Jawa. Adanya latar belakang yang bukan keturunan dari Suku Jawa, memberikan pengaruh dalam pola pengajaran anak dalam berkomunikasi dengan menggunakan bahasa Jawa di rumah. Dalam penelitian terungkap bahwa hanya $70 \%$ orang tua respdonden yang mengajarkan komunikasi dengan menggunakan bahasa Jawa di rumah. Adanya fakta ini berpengaruh dalam penggunaan bahasa Jawa untuk berkomunikasi di rumah. $70 \%$ responden mengungkapkan bahwa mereka tidak menggunakan bahasa Jawa sebagai alat komunikasi dengan orang tua mereka.

Faktor penguasaan seorang anak dalam berkomunikasi dengan menggunakan bahasa Jawa juga dapat ditunjukkan dalam nilai yang diperoleh anak dalam hasil 
studinya. Sebagaimana diketahui, untuk beberapa sekolah masih mencantumkan bahasa Jawa sebagai salah satu mata pelajaran di sekolahnya. $70 \%$ responden mengungkapkan bahwa, orangtua mereka tidak mempermasalahkan ketika si anak mendapatkan nilai yang lebih rendah untuk bahasa Jawa dibandingkan dengan nilai mata pelajaran bahasa yang lainnya. Bahkan $73 \%$ responden mengungkapkan bahwa, orang tua mereka lebih memberikan pujian yang lebih tinggi kepada si anak ketika nilai untuk mata pelajaran bahasa Inggris medapatkan nilai yang tinggi dibandingkan nila mata pelajaran bahasa Jawa.

Sekolah juga memiliki peranan yang sangat penting bagi seorang anak untuk bisa lebih menguasai bahasa Jawa. Sebagaimana diketahui bahwa pemerintah dengan beberapa peraturan yang dibuatnya, telah menetapkan bahasa Jawa sebagai salah satu mata pelajaran yang harus diajarkan di sekolah-sekolah. Dalam penelitian terungkap bahwa 93\% reponden diajarkan bahasa Jawa di sekolah mereka. Mereka mengungkapkan bahwa, bahasa Jawa sebagai mata pelajaran muatan lokal di sekolah masing-masing.

Faktor minat untuk mempelajari sebuah bahasa juga memiliki peranan penting dalam penguasaan bahasa dalam berkomunikasi. $80 \%$ responden mengungkapkan bahwa mereka memiliki minat untuk mempelajari bahasa Jawa. Minat yang tinggi untuk mempelajari bahasa Jawa pada diri si anak terkadang tidak diimbangi dengan metode pembelajaran yang tepat untuk mempelajari bahasa Jawa. Hal ini terungkap bahwa $60 \%$ responden merasa bosan ketika mempelajari bahasa Jawa di dalam kelas. Adanya inovasi dalam pembelajaran bahasa Jawa sepertinya sangat diperlukan agar anak terhindar dari kebosanan.

Terdapat tiga hal untuk menilai kemampuan seseorang dalam penguasan bahasa, yaitu kemampuan berkomunikasi dalam bentuk lisan, kemampuan untuk menulis dan lamamnion dolom mamhon. Dari ketiga kemampuan ini, rata-rata si anak masih pembelajarannya. Hal ini terlihat dari $73 \%$ responden mengalamı kseulitan dalam membaca dan menulis dalam bahasa Jawa serta masih terdapat $70 \%$ responden masih mengalami kesulitan dalam berkomunikasi dalam bahasa Jawa.

\section{KESIMPULAN}

Dari penelitian yang telah diuraikan di atas dapat diberikan kesimpulan sebagaimana berikut. Peningkatan kemampuan seseorang anak untuk berkomunikasi dalam bahasa Jawa sangat dipengaruhi oleh faktor lingkungan disekelilingnya. Faktor tersebut adalah tentang kebiasaan si anak untuk berkomunikasi dengan bahasa Jawa, baik dengan orang tua maupun dengan teman sebayanya. Penggunaan bahasa Jawa dalam berkomunikasi dalam keseharian menjadi sangat penting agar si anak dapat lebih cepat menguasai bahasa Jawa. Orang tua dan guru di sekolah memiliki peran yang sangat penting bagi seorang anak untuk meningkatkan kemampuan seorang anak untuk berkomunikasi dalam bahasa Jawa.

Dari kesimpulan tersebut dapat dilakukan beberapa hal untuk meningkatkan kemampuan seorang anak dalam berkomunikasi dengan menggunakan bahasa Jawa. Diantaranya adalah dengan melakukan inovasi dalam metode pembelajaran bahasa Jawa di sekolah, menempatkan "posisi: bahasa Jawa sama dengan mata pelajaran bahasa yang 
lainnya serta lebih meningkatkan intensitas penggunaan bahasa Jawa dalam berkomunikasi sehari-hari.

\section{DAFTAR PUSTAKA}

Akuntono, I. (2012, 9 1). Mau Tahu Jumlah Ragam Bahasa di Indonesia? Retrieved 4 7, 2019, from www.kompas.com: https://nasional.kompas.com/read/2012/09/01/12030360/Mau.Tahu.Jumlah.Raga m.Bahasa.di.Indonesia

Juhroti, S. (2011). Penggunaan Bahasa Indonesia dan Bahasa Jawa dalam Proses Pembelajaran di TK Masyitoh Kecamatan Larangan Kabupaten Brebes. Semarang: Universitas Negeri Semarang.

Mardianto, H. (1993). Bahasa dan Sastra Jawa: Antara Kenyataan dan Harapan. In A. Triyono, Pusaran Bahasa dan Sastra Jawa (p. 4). Jogjakarta: Balai Penelitian Bahawa.

Mulyana. (2008). Pembelajaran Bahasa dan Sastra Daerah Dalam Kerangka Budaya. Jogjakarta: Tiara Wacana.

Subroto, E., Dwiraharjo, M., \& Setyawan, B. (2007). Model Pelestarian dan Pengembangan Kemampuan Berbahasa Jawa Krama di Kalangan generasi Muda Wilayah Surakarta dan Sekitarnya. Surakarta: Laporan Hasil Penelitian Hibah.

Sugiyono. (2012). Metode Penelitian Kuantitatif, kualitatif dan $R \& D$. Bandung: Alfabeta.

Sutarno. (2007). Pendidikan Multikultural. Jakarta: Direktorat Jendral Pendidikan Tinggi Departemen Pendidikan Nasional.

Widada. (1993). Kondisi Bahasa Jawa dan Pemanfaatannya: Sekarang dan Masa Datang. In A. triyono, Pusaran Bahasa dan Sastra Jawa (p. 37). Jogjakarta: Balai Penelitian Bahasa.

Yudhono, J. (2011, 4 4). Anak Muda Enggan Pakai Bahasa Jawa. Retrieved 4 10, 2019, from www.kompas.com: https://nasional.kompas.com/read/2011/04/04/23160217/Anak.Muda.Enggan.Pak ai.Bahasa.Jawa 